\title{
3 Verb classification
}

An analysis of verb gradation requires a discussion of the properties of the verb, which is the graded expression. As will be shown in this chapter, the interpretation of verb gradation depends on the semantic class of the verb. This means that a different interpretation of verbal degree gradation applies for different semantic verb classes. Examples are provided in (1). In (a), sehr specifies the increase of width, whereas in (b) it is the intensity of his love.

(1) a. Der Riss hat sich sehr verbreitert.

the crack has REFL very widened

'The crack has widened a lot.'

b. Er liebt Angela sehr.

he loves Angela very

'He loves Angela very much.'

This chapter aims at discussing different types of verb classification. In 3.1, I will start with a classification of verbs based on argument alternations, as it is explicated in the work of Levin (1993). Section 3.2 discusses aktionsart-based event structural representations of verb meaning. 'Manner/result complementarity', which builds on an event structural classification of verbs and provides a lexicalization constraint on verbal roots, is discussed in 3.3. Manner/result complementarity is of relevance since it introduces the notion of 'scalar verbs.' Since scales are an essential component for gradation, this provides a natural link between verb gradation and verb semantics. Section 3.4 finally discusses the notion of the 'degree verb.' This term was introduced by Bolinger (1972) to denote gradable verbs, i.e., verbs that license degree gradation. This leads to the question what such 'degree verbs' have in common; in other words: what makes a verb gradable? Is gradability dependent on some other semantic property, like an aktionsart property, or is it independent from other semantic properties? 
There are two proposals in the literature on that topic, which will be discussed in that section. The chapter closes with a general discussion on the notion of 'gradability.'

The current chapter provides the background for later chapters by introducing relevant aktionsart properties as well as other related properties which will be relevant in chapters 6 to 8 . At the same time, the chapter presents different views on the relationship between scalarity/gradability and the lexical semantics of verbs. An essential question of this chapter is which verbs lexicalize scales, and are there any semantic constraints with respect to verbal degree gradability? The chapter will demonstrate that verbal scalarity is a much more common phenomenon than often assumed in literature, i.e., more verbs than usually thought have scales as components in their lexical semantics.

\subsection{Semantic verb classes}

In her 1993 monograph "English Verb Classes and Alternations," Beth Levin provides a classification of several thousand English verbs depending on the semantic class they belong to. The basis for her classification is diathesis alternations, i.e., alternations in the expressions of the arguments and adjuncts of a verb. The rationale of such a verb classification is characterized by Levin $(1993,11)$ as follows: "Studies of diathesis alternations show that verbs in English and other languages fall into classes on the basis of shared components of meaning. The class members have in common a range of properties, including the possible expression of certain morphologically related forms." The key idea is that the syntactic behavior of a verb depends on two properties: first, general principles of grammar and second, the meaning of the verb (Levin, 1993, 11). Whether a certain verb undergoes a diathesis alternation or not depends on the meaning of the verb, since each alternation requires the presence of a certain meaning component such as 'change of state' or 'change of location.' Therefore, verbs participating in the same alternations have to share some meaning component.

Levin uses argument alternations such as the causative/inchoative alternation in (2) or the middle alternation in (3) for her classification of verbs. 
a. The child broke the window.

b. The window broke.

(3) a. The boy cuts the bread.

b. The bread cuts easily.

The range of argument alternations Levin uses for her classification of English verbs is rather extensive and I am not going to discuss them in detail. Levin mentions that not all languages show the same range of alternations but if they do, the alternations are licensed by the same meaning components (Levin, 1993, 10f.). Frense \& Bennett (1996), for example, compare verbal alternations in German and English and show that they lead to a corresponding classification of verbs in both languages (see also Hale (2000) for a discussion of verbal alternations in O'odham (Uto-Aztecan), which also includes a broader cross-linguistic comparison). Schulte im Walde (2006) demonstrates for German that an automatic induction of semantic verb classes is possible. This automatic classification of verbs is in agreement with manually done classifications, such as the one by Levin.

Members of semantic verb classes share some properties, which include the realization of arguments, the interpretation of the arguments, the existence of morphologically related forms and - most importantly some semantic components such as, for example, causing a change of state. But semantic verb classes such as those proposed by Levin are not unquestioned. Rosen (1996) - among others - argues that these classes face several problems; for example, semantically similar verbs participate in different alternations, or the syntactic behavior of verbs is not fully governed by their lexical semantics but also depends on context. She claims that semantic verb classes are "an epiphenomenon of descriptive work on lexical semantics, argument structure, and verbal alternations" (Rosen, 1996, 193). Even if event-based accounts, as claimed by Rosen, provide a better explanation of argument linking, the concept of semantic verb classes is relevant in the context of verb gradation. What makes these classes important in the context of verb gradation is that they share the same interpretation of verbal degree gradation (this claim goes back to Ropertz (2001) and is crucial for Löbner's (2012b) claim of 'subcompositionality,' which will be discussed in chapter 9). The German examples in (4) illustrate the relevance of semantic verb classes for verbal degree gradation. In (4a) we have a change of state verb for which sehr 
specifies the extent of the change. Bluten 'bleed' is a verb of substance emission and in this case sehr indicates a great quantity of the emitted substance. Finally, ängstigen 'frighten' is a psych verb and sehr is related to the intensity of the feeling.
a. Das Kind ist sehr gewachsen.
the child is very grown
'The child has grown a lot.'
b. Die Wunde blutet sehr.
the wound bleeds very
'The wound is bleeding a lot.'
c. Der Hund ängstigt das Kind sehr.
the dog frightens the child very
'The dog frightens the child a lot.'

Degree gradation is related to different scales for all three verbs in (4). It is not only that the respective verbs in (4) differ with regard to the scale they are related to and therefore with respect to the interpretation of verbal degree gradation, but we can only observe a uniform pattern for verbs belonging to the same semantic class. This is due to the fact that degree expressions do not lexically encode a scale but require the graded predicate to contribute a suitable gradation scale. All gradable change of state verbs (e.g,. widen, broaden, lengthen) receive the same interpretation of degree gradation, the same holds for all gradable verbs of substance emission (e.g., rain, fester, hail) and gradable psych verbs (e.g., fear, love, amuse) respectively. Gradation scales can be seen as a further semantic component shared by members of certain semantic classes. But it is a semantic property that is not related to argument realization, since argument alternations do not affect verbal degree gradation. In (5) the experiencer, the one having the feeling, is realized as the subject of the verb and sehr specifies the intensity of the experiencer's feeling, whereas in (4c) it is the intensity of the feeling of the referent of the argument in object position that is indicated by sehr. Lieben 'love' as well as ängstigen 'frighten' are psych verbs; they differ in argument realization but nevertheless degree gradation shows the same effect on both verbs.

$$
\begin{aligned}
& \text { Die Frau liebt den Mann sehr. } \\
& \text { the woman loves the man very } \\
& \text { 'The woman loves the man very much.' }
\end{aligned}
$$


For psych verbs, it can be said that - irrespective of the heretogeneity of this verb class - they give access to INTENsiTy scales. ${ }^{1}$ But not all semantic verb classes license a certain type of scale. This holds in two different ways: first, some semantic verb classes, like verbs of change of possession (give, take, sell, buy), reject degree gradation completely. ${ }^{2}$ These verbs, at least in German, take neither sehr nor other degree expressions. Second, verb classes can be heterogeneous regarding scales such that some verbs accept degree expressions, whereas others do not. In German, rennen 'run' and laufen 'walk, run' can be graded by sehr (6) but gehen 'go,' as one example, cannot. Grading rennen affects the velocity of the moving entity and probably verbs of motion that do not admit degree gradation either give not access to a velocity scale or inherently specify the value of that scale in a way that is incompatible with further degree gradation. I will not speculate further on this point and not go into further detail.

Übrigens ich habe den Aufstieg in der vorgegebenen Zeit by the way I have the climb in the prescribed time geschafft, muss aber zugeben, dass ich sehr gerannt bin [...]. ${ }^{D}$ managed have to but admit that I very ran am 'By the way, I managed the climb in the prescribed time but have to admit that I ran very fast [...]'

The question of gradability will be discussed in more detail in section 3.5. Lastly, it has to be noted that the notion of 'semantic verb class' is relevant for the description of verbal degree gradation but that the classes I discuss throughout this thesis do not directly correspond to semantic classes identified by Levin. Several classes distinguished by Levin will be taken together since they exhibit uniform behavior with regard to verbal degree gradation. For each of the case studies in the later part of the thesis, I will specify how the respective classes are related to those of Levin. ${ }^{3}$

$1 \quad$ Psych verbs are heterogeneous with regard to argument realization as well as aktionsart, as will be shown in detail in chapter 8

2 Beavers (2006) in fact argues for a scalar analysis of verbs of change of possession but discussing this in detail would go beyond the limits of the thesis.

See Croft $(2012,369 f f$.) for a recent comparison of Levin's verb classification with the FrameNet approach and related work. 


\subsection{Event structure}

The term 'event structure' is used to refer to a structured lexical semantic representation of verb meaning. Verbs "individuate and name events" (Levin \& Rappaport Hovav, 2011, 424) and hence lexicalize properties of events. Event structures are, as mentioned by (Levin \& Rappaport Hovav, $2005,4)$, couched within a theory of event conceptualization which determines the properties of events that are encoded in verbs. Event structures are used for structured representations of grammatically relevant properties of event descriptions. ${ }^{4}$ Such structured representations go by different names as 'semantic forms' Wunderlich (1997), 'logical structures' (Van Valin \& LaPolla 1997; Van Valin 2005), 'event structures' (Rappaport Hovav \& Levin 1998; Levin \& Rappaport Hovav 2005) and others (cf. Levin \& Rappaport Hovav 2011). All these approaches share a common aim, namely to explain the verb's grammatical behavior, such as argument realization or verbal alternations by their inherent event structural properties. But these approaches also differ from each other in details. In the remainder, I concentrate on semantic representations as used in Role \& Reference Grammar and Levin \& Rappaport Hovav's event structures. The notion of 'event' does not occur in Role \& Reference Grammar, whereas it figures prominently in Levin \& Rappaport Hovav's work. What the authors mean by 'event' are what Bach (1986) and others call 'eventualities.' 'Eventuality' is a cover term for all situation types: states, processes and events. I will use the term 'event' to refer to non-stative situation types and use 'eventuality' to cover states as well as events.

Approaches to event structure differ with regard to the question which properties of event descriptions determine the grammatical behavior of verbs. A large number of researchers, including Van Valin and Levin \& Rappaport Hovav, take aktionsart to be the basic properties of event descriptions. Others, like Croft (1991), assume that causal relationships are the most important element in determining the grammatical behavior of verbs (cf. Levin \& Rappaport Hovav (2005) for a discussion of different approaches to event structure). Since event structures represent structured representations of grammatically relevant elements of the lexical semantics of verbs, they are usually combined with predicate decomposition. Systems

$4 \quad$ Verbs only lexicalize properties of event descriptions but not of events as such. 
of predicate decomposition use a small set of semantic primitives "to represent components of meaning that recur across significant sets of verbs" (Levin \& Rappaport Hovav, 2005, 69). Those components used in predicate decomposition are chosen to represent the grammatically relevant elements in the verb's lexical semantics. I will start by discussing aktionsart in section 3.2.1 and move on to a discussion of predicate decomposition in 3.2.2.

\subsubsection{Aktionsart}

Vendler $(1957,1967)$ proposed a four-way distinction of verbs according to their inherent temporal characteristics and distinguished the following four aktionsart classes: states, activities, achievements and accomplishments. As often mentioned in the literature, aktionsart classification does not always apply to verbs as such but rather to verbal predications ${ }^{5}$, that is verbs and arguments/adjuncts.

Three semantic features can be used to distinguish between the four Vendlerian classes: dynamicity, durativity and telicity. Dynamicity is the property that a verb refers to a situation which is conceived as a happening in the world. Stative predications are non-dynamic, while all other aktionsart classes are dynamic. States simply hold in the world, whereas events, which are dynamic, always entail some change. This notion of 'change' builds on Dowty (1979), who assumes that dynamic predications can only be evaluated over an interval of time, whereas states can be evaluated at a single moment. The second property, durativity, describes whether a verbal predication describes an eventuality that is conceived as to be extended in time. The last property is telicity, which captures the fact whether the verbal predication is taken to entail the reaching of a natural endpoint. Different theoretical explanations of the notion of 'telicity' exist - see for example the discussion in Borik (2006) - and I turn to a deeper theoretical discussion of telicity in chapter 6.

Table 9 lists the feature specifications for Vendlerian aktionsart classes. The list contains a fifth aktionsart class - semelfactive predicates - which

I use the term 'verbal predication' for referring to the respective object of an aktionsart classification, which can be either a verb or the combination of a verb with its argument(s) or adjunct(s). 
has been introduced by Smith (1997). All five classes are uniquely determined by the combination of the three features dynamicity, durativity and telicity. ${ }^{6}$

\begin{tabular}{|l|c|c|c|}
\hline & dynamic & durative & telic \\
\hline State predicate & no & yes & no \\
\hline predicate & yes & yes & no \\
\hline Achievement predicate & yes & no & yes \\
\hline Accomplishment predicate & yes & yes & yes \\
\hline Semelfactive predicate & yes & no & no \\
\hline
\end{tabular}

Table 9: Feature matrix of aktionsart properties.

The table lists stative predicates as the only stative, i.e., non-dynamic, type of predication. A state holds without a certain time limit, hence it is durative, and does not entail the reaching of an inherent endpoint. Activity predicates express a dynamic situation which also does not entail an endpoint. The two types of verbs that entail the reaching of a natural endpoint - accomplishment predicates and achievement predicates - differ with regard to durativity. The reaching of an endpoint, i.e., telicity, always implies a change in a certain property (but not vice versa). The telos, which is the entailed endpoint, can be understood as a state that holds at the end of the event but not at its beginning. Accomplishment predicates describe temporally extended changes ${ }^{7}$, whereas achievement predicates denote punctual and thereby instantaneously occurring changes. In a more restricted sense, the term 'achievement' is used for "terms that denote the culmination of a process" (Löbner, 2013, 145), i.e., punctual changes that presuppose "a dynamic initial condition" (Löbner, 2013, 145). I will not delimit the term 'achievement' in this sense and use it for punctual change verbs irrespective of whether they presuppose a certain process such as arrive or not like turn on (the light). Semelfactives, as the last class, are punctual activ-

$6 \quad$ Croft $(2012,33 f$.$) summarizes eleven aktionsart classes from literature, which cover at$ least four different types of states. Also Mori et al. (1992) argue for a finer distinction of aspectual classes and identify nine distinct classes for Japanese verbs.

7 Note that this notion of 'change' differs from the notion of 'change' that is used to characterize dynamic predicates. An explication of the former notion of 'change' will be done in section 6 . 
ity predicates. English examples of semelfactive verbs are cough or knock. These verbs are ambiguous between a semelfactive - single event reading - and an activity reading. In their activity reading these verbs denote an iteration of single events.

Before turning to the discussion of aktionsart tests, a remark regarding the use of the terms 'accomplishment' and 'achievement' is required. Above I mentioned that accomplishment predicates describe durative changes, whereas achievement predicates are punctual ones. This is in accordance with Vendler's original classification and also the use of terminology in Van Valin (2005). There is also a use of these terms that goes back to Dowty (1979). Dowty uses 'accomplishment' for causative changes, whereas 'achievements' are their non-causative counterparts. Rappaport Hovav \& Levin (1998) - among others - follow this use of terminology. I go with Vendler's original proposal and consider durativity to be the factor distinguishing between accomplishment predicates and achievement predicates rather than causativity. In fact, causativity is not taken to be a relevant aktionsart feature.

Turning now to the test criteria, different proposals in the literature exist how to test for dynamicity, durativity and telicity. The respective tests are language specific but test for the same semantic properties. For English, as one example, the progressive aspect is used to distinguish stative from non-stative predicates. ${ }^{8}$ As Comrie (1976) mentions, the progressive aspect not only requires an ongoing but also a dynamic eventuality. Since stative predicates are not dynamic, they cannot be used in the progressive aspect. Languages without a grammaticalized progressive construction cannot make use of this test criterion. In the following, I discuss test criteria which will be used throughout the remainder of the thesis. I rely on German examples to illustrate the criteria. There is much debate with respect to (i) the validity of aktionsart tests and (ii) the question as to what they are testing (e.g. Nicolay (2007) for an extensive discussion of aktionsart tests in German). I will not get into this debate and only use more or

8 To be more specific, the progressive aspect distinguishes between stage-level stative and individual-level stative predicates (Carlson 1977, Van Valin 2005, 35n3) on the one hand and between individual-level stative predicates and non-stative but durative predicates, as dynamic and punctual predicates, i.e., achievement predicates, require some type-shifting operation to be compatible with a progressive interpretation (cf. Rothstein 2004, chapter 2). 
less well accepted test criteria.

The distinction between stative and non-stative, i.e., dynamic, predicates has gained a lot of attention in the linguistic literature (Dowty 1979, Katz 1995, Rapp 1997, Maienborn 2003, Rothmayr 2009 among others). In her discussion of aktionsart classification in German, Nicolay states that most of the tests mentioned in the literature are either unreliable or test for a different property than stativity. The test she considers to be the most reliable was introduced by Gabbay \& Moravcsik (1980). This test is based on the fact that states, if they hold for a certain period of time, do so without gaps or interruptions. The authors write: "if someone knows something, then forgets, and then knows it again, we say that he rediscovered the relevant item; we count two states of knowing. Likewise, if someone is sick on a day, recovers, and becomes sick again, we say that the person was sick twice during the day" (Gabbay \& Moravcsik, 1980, 63). After an interruption, a state cannot simply continue, but a new state of the same kind begins. Rapp (1997) argues for German that if an interruption is predicated of a state, the predicate can only combine with wieder 'again' but not with weiter 'further.' Activities on the other hand, which are dynamic, are compatible with wieder as well as weiter. The examples in (7) and (8) illustrate this test for the stative predicates wohnen 'to live, to reside' and achten 'to respect.'

(7) Er wohnte drei fahre lang in Köln, nachdem er weggezogen he lived three years long in Cologne after he moved.away war, wohnte er später wieder/ ${ }^{*}$ weiter in Köln.

was lived he later again further in Cologne 'He lived in Cologne for three years, after he moved away, he lived in Cologne again.'

(8) Nachdem er sich entschuldigt hatte, achtete ich ihn *weiter/ after he REFL apologized had respected I him further wieder.

again

'After he apologized, I respected him again.'

(Nicolay, 2007, 77) 
The verbs brüllen 'yell' (9) and regnen 'rain' (10) denote dynamic eventualities and after a break the respective eventuality can either be continued or a new event of the same kind can start. ${ }^{9}$ As shown by the examples above (7)/(8), stative predications can only combine with wieder.

(9) Er brüllte 10 Minuten, und nach einer Pause brüllte er weiter/ he yelled 10 minutes and after a break yelled he further wieder.

again

'He yelled for ten minutes and, after a short break, he continued yelling/yelled again.'

(Rapp, 1997, 37)

(10) Es regnete, hörte eine Weile auf, und regnete dann weiter/ it rained stopped a while PART and rained than further wieder.

again

'It rained, stopped for a while, and then it continued raining/rained again.'

Maienborn (2003) mentions two further test criteria for stativity which she considers to be relatively reliable. The first criterion is that only dynamic predicates allow an anaphoric reference with geschehen/passieren 'happen occur,' whereas states reject it. The examples in (11) to (13) are taken from Maienborn (2003). In (11) and (12), taken from Maienborn (2003, 59f.), it is shown that eventualities denoted by dynamic predicates like (Klavier) spielen 'play (piano)' and umherlaufen 'walk around' can be anaphorically picked up by geschehen/passieren. Stative predications do not refer to eventualities which allow an anaphoric reference by geschehen/passieren as illustrated in (13) and (14), taken from Maienborn (2003, 59f.). A similar test for English by using happen for anaphoric reference is discussed in Jackendoff (1983) (also cf. Rappaport Hovav \& Levin 2000, 284).

$9 \quad$ Nicolay (2007) mentions that one has to control carefully for agentivity. A construction such as nach einer Pause 'after a break/pause' expresses an agentive interruption of the respective eventuality. One has to be careful not to mix up dynamicity with agentivity. 
(11) Shirin spielte Klavier. Das geschah/passierte während... Shirin played piano this happened/occurred while 'Shirin played piano. This happened/occurred while...'

(12) Angela lief im Garten umher. Das geschah/passierte Angela walked in.the garden around this happened/occurred während...

while

'Angela walked around in the garden. This happened/occurred while...'

(13) Heidi stand am Fenster. *Das geschah/passierte während... Heidi stood at.the window this happened/occurred while 'Heidi was standing at the window. This happened/occurred while...'

(14) Britta besaß ein Haus am See. * Das geschah/passierte Britta owned a house at.the lake this happened/occurred während...

while

'Britta owned a house at the lake. This happened/occurred while...'

The second criterion Maienborn mentions is that manner adverbs like fast and slowly are restricted to dynamic predicates and therefore are not compatible with stative predications. If they are combined with states, the state is coerced towards a dynamic reading, i.e., coming into the respective state. Maienborn's (2003: 61) examples in (15) indicate the difference in acceptability of the manner adverb schnell 'fast' for dynamic (a, b) and stative predicates $(\mathrm{c}, \mathrm{d}) .{ }^{10}$
a. Heidi lief schnell im Garten umher.
Heidi walked fast in.the garden around
'Heidi walked around quickly in the garden.'
b. Die Lampe blinkte schnell.
the light blinked fast
'The light blinked quickly.'

Mittwoch $(2013,28)$ mentions that iterative activity predicates, i.e., semelfactives, receive a different interpretation than non-iterative ones when combined with manner adverbials like fast. 
c. \#Renate wartete schnell auf Eva.

Renate waited fast on Eva

'Renate waited quickly for Eva.'

d. \#Die Briefmarke klebte schnell auf dem Brief. the stamp stuck fast on the letter

'The stamp stuck quickly on the letter.'

Not all activity predicates receive the same interpretation if combined with the adverb schnell, as illustrated by the example in (16). The only admissible interpretation in (16) is that the wound starts bleeding easily. Schnell does not indicate the speed of the emitted blood, in contrast to (15a), in which case schnell specifies the speed of Heidi.
Die Wunde blutet schnell. the wound bleeds fast
'The wound bleeds easily.'

The three test criteria mentioned above can be used together to distinguish stative predicates from activity predicates. Activity predicates, which are atelic predications, can be distinguished from accomplishment predicates by a whole battery of tests. Accomplishment predicates and activity predicates can combine with time-span adverbials like in X Zeit 'in X time' but differ in the interpretations they allow. For activity predicates, as in (17), the time-span adverbial indicates the time until the respective event starts ('ingressive reading').

Der funge schläft in einer Stunde.

The boy sleeps in one hour

'The boy sleeps in an hour.'

$\rightarrow$ After an hour, the boy starts sleeping.

$\nrightarrow$ After an hour, the boy finishes sleeping.

This reading is also possible for accomplishment predicates but in addition they allow a second interpretation in which the time-span adverbial indicates the time after which the event stops (18). Since accomplishment predicates are telic, the time-span adverbial can specify the time it takes to reach the telos ('egressive reading'). 
Der Mann repariert das Auto in einer Stunde. the man repairs the car in one hour 'The man repairs the car in an hour.'

$\rightarrow$ After an hour, the man starts repairing the car.

$\rightarrow$ After an hour, the man finishes repairing the car, i.e., after an hour the car is repaired.

Dowty (1979) mentions that expressions like almost (German fast) allow two different interpretations with accomplishment predicates (19a) - an ingressive as well as an egressive one - but only for an ingressive reading with activity predicates (19b). ${ }^{11}$ As (19c) also shows, state predicates only license an ingressive reading of fast, since they lack a telos like activity predicates do. The most obvious interpretation of sentence (19c) would be: The man lived very close to Cologne (almost in the city, but a little outside). Nevertheless, in the example I focus on the aspectually relevant ingressive reading and ignore the local reading of the sentence.

a. Der Mann hat den Wagen fast repariert.

the man has the car almost repaired

'The man almost repaired the car.'

$\rightarrow$ The man almost started repairing the car.

$\rightarrow$ The man almost finished repairing the car, i.e., the car is almost repaired.

b. Der Mann hat fast geblutet.

the man has almost bled

'The man almost bled.'

$\rightarrow$ The man almost started bleeding.

$\nrightarrow$ The man almost finished bleeding.

c. Der Mann hat fast in Köln gewohnt.

the man has almost in Cologne lived

'The man almost lived in Cologne.'

$\rightarrow$ The man almost started to live in Cologne.

$\nrightarrow$ The man almost finished living in Cologne.

See, among others, von Stechow (1996) and Beck (2005) for an analysis of the different readings of wieder in German. 
A third criterion that is useful in distinguishing activity predicates from accomplishment predicates is what Dowty (1979) calls the 'imperfective paradox' (also cf. Bennett \& Partee's 1972 'subinterval property'). Activity predicates license an entailment from the progressive (20a) to the perfect (b). As soon as someone is running, it can be said that he ran. Garey (1957, 156) states that such predicates describe situations which are realized as soon as they begin.
a. Der Mann war am Laufen, als er hinfiel. the man was at.the running when he tumbled 'The man was running, when he tumbled.'
b. Der Mann ist gelaufen. the man is run 'The man ran.'

The entailment does not go through for accomplishment predicates; the progressive sentence in (21a) does not entail the perfect one in (b). The respective process has to reach the telos to yield a true predication, thus the predication is not true as soon as the denoted event starts. It is not true that as soon as the process of stabilization has started, the condition has stabilized. Situations denoted by telic predicates are not realized as soon as they begin.
a. Der Zustand des Patienten war sich am Stabilisieren, the condition of.the patient was REFL at.the stabilizing als er verstarb. when he died 'The condition of the patient was stabilizing when he died.'
b. Der Zustand des Patienten hat sich stabilisiert. the condition of.the patient has REFL stabilized 'The condition of the patient has stabilized.'

At last, criteria to distinguish punctual predications, i.e., achievements and semelfactives, from durative ones need to be introduced. Punctual predicates get an iterative interpretation if they are combined with durative time adverbials such as $X$ Zeit lang 'for X time.' The verb klopfen 'knock' can have a semelfactive reading, meaning that a single knock was produced (22a). By adding the time-adverbial zehn Minuten lang 'for ten minutes,' the 
only interpretation is that the man knocked repeatedly for ten minutes. No one would make the interpretation that it took him ten minutes to make a single knock. For activity predicates, as in (22b), the durative adverbial measures the temporal extent of the event (cf. Mittwoch 2013). This is also the effect for (22a) but requires an iterative and therefore activity reading of the predicate. ${ }^{12}$
a. Der Mann klopfte zehn Minuten lang an die Tür. the man knocked then minutes long at the door 'The man knocked at the door for ten minutes.'
b. Der Mann lief zehn Minuten lang. the man ran ten minutes long 'The man ran for ten minutes.'

Also some achievement predicates get an iterative interpretation if combined with durative time adverbials. Sentence (23a) has the reading that Angela scared her friend repeatedly for ten minutes. If an accomplishment predicate is combined with a durative adverbial, telicity is canceled and the verb is shifted towards an activity reading (cf. Engelberg (1994) for a discussion of the combination of accomplishment predicates and durative time adverbials in German). In (23b) it is only expressed that the man was engaged in the activity of reparing his car for an hour but it is not entailed that after an hour the car is repaired. In contrast to achievement predicates, the durative adverbial does not induce a repetitive interpretation of the process.

(23) a. Angela erschreckte ihren Freund zehn Minuten lang. Angela scared her friend ten minutes long 'Angela scared her friend for ten minutes.'

b. Der Mann reparierte das Auto eine Stunde lang. the man repaired the car one hour long 'The man repaired the car for an hour.'

12 Further criteria for identifying semelfactive predicates are discussed in Rothstein (2004). 


\subsubsection{Predicate decomposition}

Predicate decompositions are "representations of meaning formulated in terms of one or more primitive predicates chosen to represent components of meaning that recur across significant sets of verbs" (Levin \& Rappaport Hovav, 2005, 69). The aim of using predicate decompositions is to provide a structured representation of grammatically relevant meaning components of verbs. These meaning components are not stipulated for each verb separately, but capture meaning elements which are shared by verbs showing similar grammatical behavior. Predicate decompositions are used for representing event structures. There are different ways of using these structures for representing events: events can either be left implicit represented as predicate decompositional structures are understood as event descriptions or events can be explicitly introduced into these representations - as an event variable - and thereby function as an argument of the decompositional predicates. Van Valin as well as Rappaport Hovav and Levin go the first way, for the second option see, for example, Rothstein (2004).

Each system of predicate decomposition makes use of a limited set of primitive predicates such as for example do' in RRG or ACT in Levin \& Rappaport Hovav's account. These predicates (or operators as they are called in RRG) are used to represent the relevant aktionsart characteristics even if they do not directly represent the aktionsart properties discussed in the last section. So there is no predicate expressing stativity or telicity; nevertheless, the set of basic predicates is used to represent aktionsart classes. Beside these predicates, each decompositional system has a way of expressing the idiosyncratic content which distinguishes verbs belonging to the same aktionsart classes. For example, know and believe are both stative predicates and share the same structural representation, but they are differentiated by their idiosyncratic content. Van Valin (2005) uses the term 'predicate' to refer to the elements expressing the idiosyncratic content, whereas Levin \& Rappaport Hovav (2011) and Rappaport Hovav \& Levin (2010) call it 'root.'

As a starting point, I take Van Valin's predicate decomposition, which is based on Dowty (1979). One reason for choosing this approach is that I will make use of Role \& Reference Grammar (RRG; Foley \& Van Valin 1984; Van Valin \& LaPolla 1997; Van Valin 2005) in later parts of the thesis 
(especially chapter 4). Van Valin assumes two basic types of predicates, which function as the building blocks for other predication types. These are states on the one hand and activities on the other hand. ${ }^{13}$ This means that achievements, accomplishments and semelfactives are derived from state or activity predicates. States are represented as plain predicates, as in (24). The general scheme for states is shown in (a), whereas (b) and (c) shows its instantiation for two example verbs.

STATE: predicate' $(\mathrm{x})$ or predicate' $(\mathrm{x}, \mathrm{y})$

a. know: know' $(\mathrm{x}, \mathrm{y})$

b. believe: believe'(x, y)

Activity predicates are always marked by the two-place predicate do'. The first argument of do' is the actor, which is $x$ in (25) and the second argument is itself a one- or two-place predicate that introduces the idiosyncratic content of the overall predication. In (25) the general scheme for activities is shown in (a), as well as two sample instantiations for that predicate type $(b, c)$.

ACTIVITY: do' $\left(\mathrm{x},\left[\right.\right.$ predicate' $\left.\left.\left.^{\prime} \mathrm{x}\right)\right]\right)$ or do' $\left(\mathrm{x},\left[\right.\right.$ predicate' $\left.\left.\left.^{\prime} \mathrm{x}, \mathrm{y}\right)\right]\right)$

a. run: do' $\left(\mathrm{x},\left[\right.\right.$ run' $\left.\left.^{\prime}(\mathrm{x})\right]\right)$

b. kiss: do'(x, $\left.\left[\mathbf{k i s s}^{\prime}(\mathrm{x}, \mathrm{y})\right]\right)$

The predicates that show up as the second argument of do' are always preceded by it and never occur alone. do' itself functions merely as a marker for activities and evidence for such an operator is provided by Basque (26) taken from Van Valin \& LaPolla (1997, 104). They mention that Basque makes use of a light verb construction consisting of the verb egin 'do' and a noun for predications which in English are expressed as intransitive activities.

$$
\begin{aligned}
& \mathrm{Ni}-\mathrm{k} \quad \text { lan- } \emptyset \text { egin } d-u-t . \\
& \text { 1sG-ERG work-ABS do 3sG.ABS-AUX-1sG.ERG } \\
& \text { 'I worked.' (literally: 'I did work.') }
\end{aligned}
$$

13 In the remainder, I use the terms 'state', 'activity', 'accomplishment', 'achievement' and 'semelfactive' as a short form for 'stative predicate', 'activity predicate', and so on. But one has to carefully keep in mind that die, for example, is not an achievement but an achievement predicate. 
The other aktionsart classes are derived by adding further operators to the basic predicate types. Achievements are derived by adding the INGR (ingressive) operator, which is used to mark punctual changes of state (27a) or punctual onsets of activities. An example of the first type is shown in (27a), whereas a punctual onset of an activity is shown by the Russian example in (27b).

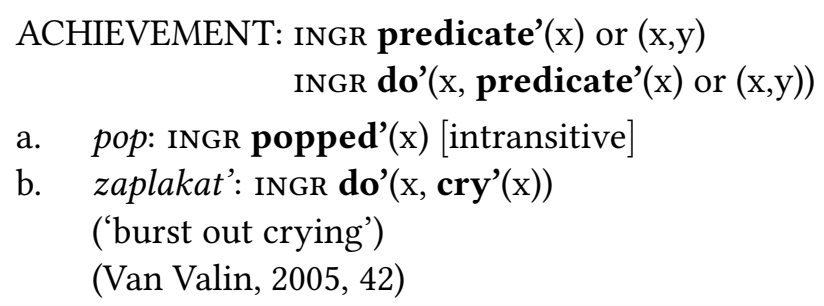

a. pop: INGR popped'(x) [intransitive]

b. zaplakat': INGR do'(x, cry'(x))

('burst out crying')

(Van Valin, 2005, 42)

The operator Become, which is defined in Dowty $(1979,76)$, is used to derive accomplishment predicates. BECOME can be added to a state or activity predicate to mark a temporally extended change of state (28a) or a non-punctual onset of an activity. The latter is illustrated by the Russian example in (28b), which is taken from Van Valin $(2005,42)$.

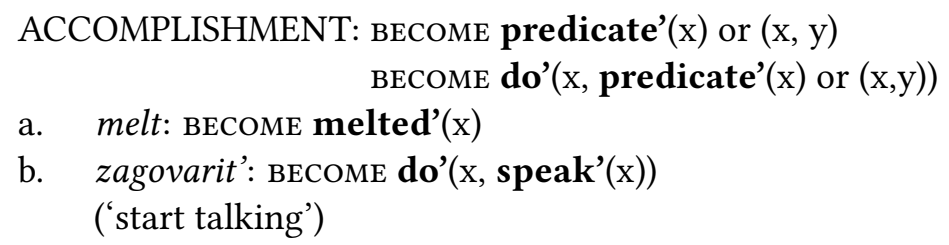

If an accomplishment or achievement is derived from a state predicate, the state predicate stands for the attained result state. An activity predicate stands for the respective activity into which the actor goes over. ${ }^{14}$ A last operator is SEML, which is used to mark punctuality of states or activities. In Van Valin's approach, stative as well as activity predicates can serve as the basis for semelfactives (29).

(29) SEMELFACTIVE: SEML predicate' $(x)$ or $(x, y)$

a. glimpse: SEML see'( $\mathrm{x}, \mathrm{y})$

SEML do'( $\mathrm{x}$, predicate' $(\mathrm{x})$ or $(\mathrm{x}, \mathrm{y}))$

b. cough: SEML do'(x, cough'(x))

14 I leave out the discussion of 'active accomplishments' but see Van Valin (2005). 
Russian has a morphological marking of semelfactives. By adding the morpheme $-n u$ to a non-punctual activity, a semelfactive is derived (30). Prygat' 'jump' and kričat' 'shout' are imperfective verbs; the derived semelfactives, on the other hand, are perfective. Hence, the affix -nu not only changes the aktionsart of the predicates, but also affects the grammatical aspect.

$$
\begin{aligned}
& \text { a. prygat' prygnut' } \\
& \text { b. jump' 'jump once' } \\
& \text { kričat' kriknut' } \\
& \text { 'shout' 'shout once' }
\end{aligned}
$$

CAUSE is a further operator within the decompositional approach but it is not used to derive an aktionsart class from a basic state or activity predicate. Rather it is an additional operator which represents a grammatically relevant meaning component. The operator CAUSE is used to represent a causal relationship between two subevents. The operator takes two formulas $-\alpha$ and $\beta-$ as its arguments (31). Examples of causative predicates are shown in (a) and (b), which are the causative uses of melt and pop respectively. The non-causative uses have been represented above in (27a) and (28b). In both cases, the causing subevent is unspecified, it is merely expressed that some activity causes the respective change of state. ' $\emptyset$ ' is used to represent an unspecified activity.

\section{CAusative $\alpha$ CAUSE $\beta$}

a. melt: $\left[\mathbf{d o}^{\prime}(\mathrm{x}, \emptyset)\right]$ CAUSE [BECOME melted'(y)]

b. pop: $\left[\mathbf{d o}^{\prime}(\mathrm{x}, \emptyset)\right]$ CAUSE [INGR pop' $\left.(\mathrm{y})\right]$

Since causality is not an aktionsart property, test criteria for causality have not been discussed in the last section. At this stage, I would like to introduce two criteria that can be used for testing for causality. First, causative predicates allow for an explicit causative paraphrase (Van Valin, 2005, 38). In English, the verb cause explicitly shows up in such a paraphrase, as can be seen in (32a). Such a causative paraphrase is appropriate for frighten, but as (b) indicates it is not for fear. To be an appropriate paraphrase, the number and order of arguments have to be the same in the paraphrase and the paraphrased predication. Causativity is independent from agentivity as the dog in (32a) can either be agentively engaged in frightening the boy 
or merely the source of the boy's fear without doing something to cause the fear. It could probably be merely the presence of the dog that causes the boy to feel fear.
a. The dog frightened the boy.
$\rightarrow$ The dog caused the boy to feel fear.
b. The boy feared the dog.
$\nrightarrow$ The dog caused the boy to feel fear.

A second criterion is based on VanValin \& Wilkin's (1996) distinction between 'implements' and 'instruments.' Instruments are "manipulated inanimate effectors" (Van Valin, 2005, 59), which are embedded in a causal chain. In (33) the logical structure for the sentence Leslie shattered the window with a rock. is shown. The instrument rock is embedded in a causal chain, since it can be taken as an intermediate causer of the shattering of the window. Typically, instruments allow the instrument-subject alternation (cf. Levin 1993, 80) as in (34).

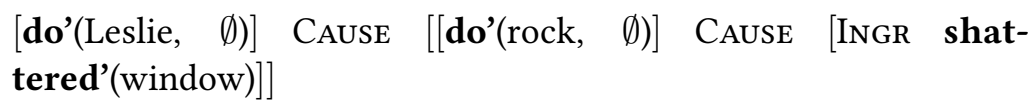

(34) a. Leslie shattered the window with a rock.

b. The rock shattered the window.

Implements are not embedded in a causal chain and are added to an activity structure, which is further modified by the implement. This is illustrated with the example sentence Chris ate the soup with a spoon. in (35). The implement is added to the structure by the predicate use' and the connective ' $\wedge$,' which in this case means 'and simultaneously.'

$$
\begin{aligned}
& \text { do'(Chris, [eat'(Chris, soup) } \wedge \text { use'(Chris, spoon) }]) \\
& (\text { Van Valin, 2005, 59) }
\end{aligned}
$$

Evidence for a different treatment of instruments and implements is provided by the fact that implements do not participate in the subjectinstrument alternation (36).

(36) a. Chris ate the soup with a spoon.

b. \#The spoon ate the soup. 
The decompositional system employed by Levin \& Rappaport Hovav is similar to Van Valin's and also based on Dowty (1979). Levin \& Rappaport Hovav distinguish between structural and idiosyncratic components of verb meaning and write: "The structural part of a verb's meaning is that part which is relevant to determining the semantic classes of verbs that are grammatically relevant, whereas the idiosyncratic part of a verb's meaning distinguishes that verb from other members of the same class" (Rappaport Hovav \& Levin, 1998, 106). Idiosyncratic parts of verb meaning are also called 'roots' and function either as the modifier of a structural component or as its argument. In (37) a slightly revised version of Rappaport Hovav \& Levin's $(1998,108)$ event schema is shown. Roots are written in angled brackets and come in two basic types. They either denote a state, which functions as the sole element of a stative predicate, or as the argument of Become. In the latter case, the root is called 'result root.' ${ }^{15}$ The second type is called 'manner root' and functions as a modifier of an AcT predicate. The distinction between 'manner' and 'result' will be discussed in the next section, at the current stage only a description of Rappaport Hovav \& Levin's event schemata is intended.
a. State: $[x\langle$ STATE $\rangle]$
b. Activity: $\left[\mathrm{x} \mathrm{ACT}_{\langle\mathrm{STATE}\rangle}\right]$
c. Achievement: [BECOME $[\mathrm{x}\langle$ RESULT $\rangle]]$
d. Accomplishment: [x CAUSe [Become $[\mathrm{y}\langle$ RESUlt $\rangle]]]$

The differences between Van Valin's approach and the one of Rappaport Hovav \& Levin consist basically in a different analysis of achievements and accomplishments on the one hand and on the other hand in the use of different operators for activity predicates. ${ }^{16}$ Rappaport Hovav \& Levin (1998) follow Dowty in assuming that causality is the differentiating factor between achievements and accomplishments and not durativity. With regard to the second point, Rappaport Hovav and Levin use a one-place

\footnotetext{
15 The authors do not specify whether result roots are a subytpe of plain state roots or whether they are distinct types. I assume result roots, which denote result states, to be a subytpe of states in general.

16 Although Levin (1999) identifies semelfactives as a separate class, she assigns them the same event structural template then activities. Following Levin, the difference between semelfactives and activities is not in the structural but in the idiosyncratic meaning component.
} 
predicate Act instead of Van Valin's two-place predicate do'. This goes together with the notion of a root and how the root is integrated into the decompositional structure. Van Valin does not make use of the term 'root' but it corresponds to the predicates in his decompositional system. In the case of activities, the root is taken to be a modifier by Rappaport Hovav \& Levin, whereas Van Valin takes it to be the second argument of do'. For the following discussion, I equate Van Valin's predicates with Rappaport Hovav \& Levin's notion of a 'root.' Roots are the central target in the discussion of manner/result complementarity to which I turn in the next section.

\subsection{Manner/result complementarity}

'Manner/result complementarity' is a constraint on the lexical content of monomorphemic predicates. ${ }^{17}$ It is not so much this lexicalization constraint that is relevant for the current thesis but Rappaport Hovav \& Levin's explication of result verbs as 'scalar verbs.' They propose a natural link between the notion of 'result' and scalarity. The assumption behind the manner/result complementarity is that a constraint of the following type holds: each monomorphemic predicate only lexicalizes a single root Rappaport Hovav \& Levin $(1998,2010)$. This classification only applies to dynamic verbs; it does not cover stative predications. The manner/result complementarity means that each monomorphemic verb either lexicalizes a manner or a result root and not both at the same time. Manner/result complementarity imposes a constraint on possible event structures. The event structures in (38a) to (c) are possible for monomorphemic verbs; in each case the structure contains just one root. In (c) the root indicates the result state, since result roots are arguments of BЕсомE, whereas manner roots are modifiers of Аст. Structures (d) and (e) are excluded for monomorphemic verbs, since in this case two roots would be lexicalized.

$$
\begin{array}{ll}
\text { a. } & {\left[\mathrm{x} \mathrm{ACT}_{\langle\text {RоOт }\rangle}\right]} \\
\text { b. } & {[\operatorname{BECOME~}[\mathrm{x}\langle\text { ROOT }\rangle]]}
\end{array}
$$

For a critical discussion of the manner/result complementarity cf. Beavers \& KoontzGarboden (2012), also see the discussion in Levin \& Rappaport Hovav (2013) and the literature cited therein. 
c. $[\mathrm{X}$ ACT $]$ CAUSE $[$ BECOME $[\mathrm{x}\langle$ ROOT $\rangle]]$

d. * $*\left[\mathrm{x}\right.$ ACT $\left.{ }_{\langle\text {ROOT } 1\rangle}\right] \operatorname{CAUSE}[\operatorname{BECOME}[\mathrm{x}\langle$ ROOT2 $\left.\rangle]]\right]$

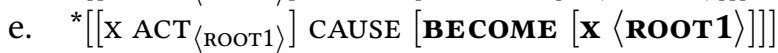

(based on Beavers \& Koontz-Garboden 2012, 333)

The structure in (d), unlike the one in (e), is possible for complex, i.e., derived verbs. (38e) is excluded since a single root would simultaneously specify manner and result. A case in which manner and result are contributed by different elements in a complex verb is indicated by the Lakhota examples in (39). The result root is contributed by the stem t' $a$ 'die, be dead' and the manner component is added by the instrumental prefix. The instrumental prefix $y a$-indicates an action with the mouth, wa- an action with a sawing motion/a knife, wo- an action from a distance and $y u$ - an action with the hands. ${ }^{18}$

Lakhota (Siouan; Foley \& Van Valin 1984, 41ff.)
a. $y a-t$ ' $a$ 'bite to death'
b. wa-t'a 'stab to death'
c. wo-t'a 'shoot to death'
d. $y u-t$ ' $a$ 'strangle to death'

The German examples in (40) show the opposite pattern to the Lakotha one. It is the verb in (40) that specifies the manner, whereas the result is derived in the process of prefixation.

$$
\begin{aligned}
& \text { stechen er-stechen } \\
& \text { 'stab' 'stab to death' }
\end{aligned}
$$

For this thesis, it is relevant that manner/result complementarity provides a classification of dynamic verbs into 'manner verbs' and 'result verbs.' But even more interesting is Rappaport Hovav \& Levin's explication of the notions of 'manner' and 'result' in terms of 'scalar changes.' As mentioned in 3.2, all dynamic predicates express changes. But manner and result verbs differ with respect to the nature of the change they express. Result verbs express scalar changes, which are directed changes in a single, specified dimension. This kind of change can be characterized as progression along

18 The examples in (39) are not exhaustive as Lakhota has further instrumental prefixes see Van Valin (1977, 19ff.) and Foley \& Van Valin (1984, 41ff.). 
a scale. Explicating the notion of 'non-scalar change,' Rappaport Hovav \& Levin $(2010,32)$ write: "A non-scalar change is any change that cannot be characterized in terms of an ordered set of values of a single attribute." Two different types of non-scalar changes can be distinguished: (i) undirected changes and (ii) changes in multiple dimensions. An example of an undirected change is provided by the verb cross. Rappaport Hovav \& Levin $(2010,30)$ state that the direction of the crossing is unspecified and hence the change not directed. A crossing of the British Channel may either occur from England to France or from France to England. The verb itself is compatible with a movement in both directions. Scalar change verbs are directed, a change expressed by grow always entails an increase in size and is not compatible with a decreasing size of the changing entity. The second type of non-scalar change can be illustrated by the verb jog. Rappaport Hovav \& Levin $(2010,33)$ write: "[E]ven though there is a sequence of changes specified by jog, collectively these changes do not represent a change in the values of a single attribute, nor is any one element in the sequence of changes privileged as being the necessary starting point of motion." fog expresses changes in different dimensions, as - among other changes - changes in the positioning of the arms of the jogger, of the legs and of the entire location. Hence, the verb does not isolate a single dimension for which it expresses a change. Based on this interpretation of the notions of 'manner' and 'result,' the manner/result complementarity might be rephrased as I do in (41).

Rephrasing of manner/result complementarity:

All dynamic (monomorphemic) verbs either express non-scalar or scalar changes. No such verb encodes both at the same time.

Rappaport Hovav (2008) lists three properties that are characteristic of scalar change verbs. These characteristics, which can be used to separate scalar and non-scalar change verbs from each other, are listed in (42), based on the formulation by Fleischhauer \& Gamerschlag $(2014,35)$.

(42) a. Scalar verbs are restricted to result-XPs that are compatible with the lexicalized scale.

b. Scalar verbs can be telic without a measure phrase or explicit event delimitation. 
c. Scalar verbs do not allow for the deletion of the theme argument.

The basic idea underlying the properties in (42) is that the presence of a scale measuring a change affects the grammatical behavior of verbs. I discuss the three properties separately, beginning with the one in (a). Rappaport Hovav states that scalar change verbs are more restricted regarding possible result-XPs than non-scalar change verbs. The rationale behind this idea is that result-XPs are taken to be scale-denoting expressions. A result-XP is either an adjectival phrase as in (43a) or a prepositional phrase like in (b). The adjective denotes an endpoint on a scale, in this case a twopoint scale consisting of the two values 'alive' and 'dead.' In (b), the change occurs along a multivalue scale and ends up at a value of 80 degrees.
a. Der Mann schlägt seinen Nachbarn tot. the man hits his neighbor dead 'The man beats his neighbor to death.'
b. Das Wasser erhitzt sich auf $80 \mathrm{Grad}$. the water heats REFL up 80 degrees 'The water heats up to 80 degrees.'

The notions of 'two-point' and 'multivalue scales' is used by different authors such as Beavers (2008, 2013), Rappaport Hovav (2008) or Rappaport Hovav \& Levin $(2010)$. Chief $(2007,11)$ uses instead the notions of 'complex scale,' which consists of at least three values, and 'simple scale,' consisting of merely two degrees. A two-point scale only has two values, which are contradictory to each other; in the case of (43a) the man is either dead or alive and there is no further possibility. In case of a multivalue scale, the values form a contrary set. Two-point scales are nominal scales and therefore do not qualify as scales in the sense of Kennedy \& McNally (cf. the discussion in section 2.2). ${ }^{19}$

Beavers $(2008,2013,690)$ explicitly states that two-point scales are not gradable and gradable terms are related to multivalue scales. Beavers, Rappaport Hovav and Rappaport Hovav \& Levin use scale for an explication of the notion of 'change' and Beavers $(2013,684)$ writes: "[...] change is defined

See Bolinger $(1967,7)$ for the view that scales have to consist of at least three values and hence two opposed values do not constitute a scale. 
as some theme transitioning to and maintaining a new value along some property scale $[. .$.$] ". The reason for postulating two-point scales in addi-$ tion to multivalue scales is to provide a uniform analysis of result verbs as scalar, irrespective of whether they are punctual or not. A punctual change is a change on a two-point scale, whereas a temporarily extended change progresses along a multivalue scale. I adopt this broad notion of scalarity as it allows characterizing all change of state verbs as scalar verbs, but degree gradation, as will be shown in chapter 5 , is restricted to multivalue scales. Therefore, the notion of a 'two-point scale' will be not of crucial relevance for the analysis and nothing hinges on this notion.

Going back to resultative constructions as in (43), the common core of (43a) and (b) is that in both cases a change of state is predicated. In (a) the neighbor changes from being alive to being dead, whereas in (b) the temperature of the water changes up to 80 degrees. The difference between (a) and (b) is that only in the latter case a change of state, i.e., a scalar change, is already entailed by the verb erhitzen 'heat up.' Even without a result-XP, the verb erhitzen expresses a scalar change in a single dimension of the referent of the theme argument Wasser 'water.' This is different for (a), the verb schlagen 'hit' does not express a scalar change. No specific result is entailed by the verb and a change of state predication only arises by the addition of the result-XP. Washio (1997) and Kaufmann \& Wunderlich (1998) call resultative constructions as in (43a) 'strong resultatives' whereas those of the type in (b) are called 'weak resultatives.' In the case of weak resultatives, the result-XP further specifies an already lexically encoded result.

Rappaport Hovav claims that verbs which do not lexically encode a scalar change are less restricted with regard to result-XPs than those which do. The reason is that if a verb expresses a scalar change, the result-XP has to be compatible with the change denoted by the verb. This means that the result-XP has to denote a value that belongs to the scale lexicalized by the verb. Since non-scalar change verbs do not express a change measured on a scale, they do not provide such a restriction on result-XPs and hence allow a broader range of resultative-XPs. In (44) the contrast between a scalar and two non-scalar verbs regarding resultative-XPs are shown. The scalar verb gefrieren 'freeze' in (a) is very restricted with respect to possible resultative-XPs. Essen 'eat' on the one hand and schreien 'cry' are compat- 
ible with a broader range of result-XPs. The relevant fact is that $z u$ Eis 'to ice' denotes a natural endpoint of a change denoted by gefrieren. In (c), for example, the resultative-XPs belong to different types of scales; hoarse and to sleep do not denote values that belong to the same dimension. Thus the verb does not provide such a neat restriction on resultative-XPs than found by scalar verbs. ${ }^{20}$
a. Der Fluss gefror zu Eis/ \#breit/ \#tief. the river froze to ice wide deep 'The river froze solid/\#wide/\#deep.'
b. Peter aß sich \#groß/ krank/ fett/ zu Tode/ glücklich. Peter ate REFL tall ill fat to death happy 'Peter ate himself \#tall/sick/fat/to death/happy.'
c. Das Kind schrie sich heiser/ in den Schlaf. the child cried REFL hoarse in the sleep 'The child cried itself hoarse/to sleep.' (Fleischhauer \& Gamerschlag, 2014, 35)

The second property of scalar verbs is that they allow a telic interpretation even without explicit event delimitation. This clearly holds for verbs like repair in (45), but as Rappaport Hovav \& Levin $(2010,27)$ mention telicity fails to appropriately distinguish between scalar and non-scalar change verbs. Some clearly scalar verbs denote atelic changes of state, as for example German wachsen 'grow' (46).

(45) The man repaired the car in one hour.

(46) a. \#Das Kind ist in einem fahr gewachsen. the child is in one year grown

b. Das Kind ist in einem fahr zehn Zentimeter gewachsen. the child is in one year ten centimeters grown 'The child has grown ten centimeters in one year.'

20 The first criterion only holds for Talmy's (2000) 'satellite-framed languages' like German and English but it does not hold for 'verb-framed languages' such as French or Spanish. The latter only allow strong resultatives, i.e., resultative constructions with scalar verbs (see Gehrke 2008 among others). 
Change of state verbs like wachsen, which are either atelic or show variable telicity, are called 'degree achievements' following Dowty (1979). ${ }^{21}$ Many degree achievements as German verbreitern 'broaden,' verlängern 'lengthen' or verkleinern 'diminish' are derived from gradable adjectives and provide the prototypical instances of scalar verbs. I will discuss these verbs in more detail in chapter 6 . The relevant aspect shown by these verbs is that Rappaport Hovav's second property of scalar verbs is merely a sufficient but not a necessary one, since all telic verbs are scalar but not all scalar verbs are telic.

The third property is concerned with argument realization patterns of scalar and non-scalar verbs. Scalar verbs do not license the omission of the undergoer argument, whereas non-scalar verbs often do. Taking (47) as an example, the transitive verb denotes a caused change in the undergoer, which is die Straße 'the street.' During the event denoted by the verb, the street increases in width. The change is measured on a width-scale and the entity that is measured on the scale is die Straße. As (b) shows, if the actor die Arbeiter 'the workers' is realized as the single argument of the verb, the sentence is odd. Example (c) shows that the undergoer can be the single argument of the verb without turning the sentence to ungrammaticality.
a. Die Arbeiter ${ }_{C a u s e r}$ verbreiterten die Straße $_{\text {Theme }}$. the workers widened the street 'The workers ${ }_{\text {Causer }}$ widened the street Theme.' .
b. ${ }^{*}$ Die Arbeiter Causer $_{\text {verbreiterten. }}$ the workers widened
c. Die Straße Theme verbreiterte sich. the street widened REFL 'The street ${ }_{\text {Theme }}$ widened.' (Fleischhauer \& Gamerschlag, 2014, 36)

The reflexive pronoun sich in (47c) marks the causative/inchoative alternation with change of state verbs in German. This alternation and the marking by the reflexive will be discussed in more detail in chapter 6 . But note that the use of the reflexive in (47c) differs from fake reflexives as in

\footnotetext{
21 As mentioned above, Dowty's use of the term 'achievement' differs from how I use that term. But I stay with the notion of 'degree achievement' since it is well established, even if 'degree accomplishments' would be more correct.
} 
the resultative constructions in (44b) and (c). In the latter cases, the change is predicated over the referent of the reflexive, whereas in (47) it does not function as an argument but merely as a marker of the anticausative.

Non-scalar change verbs freely allow the omission of the undergoer argument (called 'unspecified object alternation' in Levin $(1993,33)$ and 'antipassive' in Löbner $(2013,137)$ as exemplified in (48). In contrast to scalar change verbs, an ungrammatical sentence arises if only the undergoer argument is realized (48c). A further difference from scalar verbs is that the non-scalar verbs do not require a special marking - for example, in terms of the reflexive pronoun sich - for an intransitive use. Following Rappaport Hovav, the reason for the non-omissability of the undergoer argument of scalar verbs is that the entities measured on a scale need to have an overt realization.

$$
\begin{aligned}
& \text { a. } \text { Peter }_{\text {Agent }} \text { aß das } \text { Brot }_{\text {Theme. }} . \\
& \text { Peter ate the bread } \\
& \text { 'Peter } \text { Agent }_{\text {ate the bread }} \text { Theme.' } \\
& \text { b. Peter aß. } \\
& \text { Peter ate } \\
& \text { 'Peter } \text { Agent }_{\text {ate.' }} \\
& \text { c. 'Das Brot } \text { Thema }_{\text {a }} \text { aß (sich). } \\
& \text { the bread ate REFL } \\
& \text { (Fleischhauer \& Gamerschlag, 2014, 36) }
\end{aligned}
$$

There is some debate as to whether incremental theme verbs are lexically scalar (e.g. Beavers 2012; Kardos 2012 or whether the respective scale is introduced by the incremental theme argument via argument composition. Rappaport Hovav and Rappaport Hovav \& Levin advocate the latter position, since incremental theme verbs do not show the characteristics of scalar change verbs, as the examples above have shown. Hence, these verbs are not lexically scalar, but express a change on a scale that is compositionally derived. Scalar change verbs, i.e., verbs that lexically express a scalar change, comprise the class of change of state verbs and also some directed motion verbs like enter or exit. Incremental theme verbs as well as some other directed motion verbs, for example cross, are not lexically scalar but, in some of their uses, express changes on compositionally derived scales. The presence and nature of the scale is dependent on the (incremental) 
theme argument (see Rappaport Hovav 2008; Rappaport Hovav \& Levin 2010; Kennedy 2012).

Rappaport Hovav relates the three mentioned classes of verbs (change of state verbs, incremental theme verbs and verbs of directed motion) to different types of scales as summarized in table 10 .

\begin{tabular}{|l|l|l|}
\hline \multicolumn{1}{|c|}{ scale type } & \multicolumn{1}{c|}{ verb class } & \multicolumn{1}{c|}{ examples } \\
\hline property scale & change of state verbs & widen, darken, grow \\
\hline path scale & verbs of directed motion & enter, exit, cross \\
\hline volume/extent scale & incremental theme verbs & eat $N$, drink $N$, read $N$ \\
\hline
\end{tabular}

Table 10: Scale type and verb class relationship, based on Rappaport Hovav (2008).

Change of state verbs are related to property scales that represent some property as 'size' or 'weight' of the referent of the theme argument. Such scales are always lexicalized by the respective verbs. Volume/extent scales are always compositionally derived and introduced by the incremental theme argument. These scales measure the volume/extent of the referent of the incremental theme argument and how much of it is affected by the event. Path scales, to which verbs of directed motion are related, are lexicalized by some verbs but not by others. If the verb denotes a movement to a definite endpoint, Rappaport Hovav as well as Rappaport Hovav \& Levin assume that the verb lexicalizes a path scale. If no such definite spatial transition is expressed, the verb is taken to be non-scalar and scales are compositionally derived.

In chapter 6, I discuss change of state verbs in detail and raise the question of what it means that a verb lexicalizes a scale. For the current discussion, the focus is put on the claim that only change of state verbs (and a subset of verbs of directed motion) are scalar verbs and that the notion of 'scalarity' is relativized to the expression of directed changes in a single dimension. 


\subsection{Degree verbs}

The notion 'degree verbs' goes back to Bolinger and is negatively defined: "[a] nondegree verb does not accept intensifiers" (Bolinger, 1972, 160). Hence, degree verbs are verbs that accept what Bolinger calls 'intensifiers,' as indicated by his examples in (49). The sentences marked with an asterisk contain nondegree verbs, whereas those without an asterisk contain degree verbs.
a. Why do you hesitate so?
b. *Why do you wait so?
c. Don't struggle so.
d. *Don't perform so.
e. Why did you bury it 'get it so deep'?
f. * Why did you inter it so?
(Bolinger, 1972, 160)

Bolinger is well aware of the distinction between extent and degree gradation, which in fact goes back to his work. He writes that extent gradation is almost universal among verbs and so he considers extent gradability not to be a relevant property for being a degree verb. Rather he writes: "Verbs like talk, dance, swim, reach, leave, sleep, etc. are nondegree and normally intensified, like plural and mass nondegree nouns, only for extensibility" (Bolinger, 1972, 161). In (50) dance is intensified for the extent of the event, or the amount of dancing as (Bolinger, 1972, 161), puts it. But, as he further states, it rejects degree gradation and therefore does not qualify as degree verb.
a. Such dancing all the time.
b. I wish they wouldn't dance so all the time.
(Bolinger, 1972, 161)

Similar to the adjectival domain, Bolinger conceives gradability as a property to classify verbs. Gradability can be used to distinguish between gradable and non-gradable adjectives, gradable adjectives admitting degree morphology as the comparative morpheme in languages such as English and German, whereas non-gradable adjectives either reject it or require some coercion (cf. chapter 2). Bolinger's distinction between degree and 
nondegree verbs is similar, verbs that accept expressions for degree gradation are degree verbs, and those that do not are nondegree verbs. This leads to the questions which property, beyond the acceptability of degree expressions, is shared by the class of degree verbs, if they share some relevant property at all. There are two actual proposals, by Tenny (2000) and Tsujimura (2001), on the semantic properties licensing degree expressions. Both proposals make use of event structure and are discussed sequentially in the following sections. In this chapter, I concentrate on 'degree gradability' and will not discuss the conditions licensing extent gradation; but see Doetjes $(1997,2007)$ for a discussion of extent gradability.

\subsubsection{Tenny (2000) on 'measure adverbs'}

Tenny (2000), based on the work of Travis (2000), argues basically that event structure is reflected in syntax, meaning generative grammar style syntax. Different parts of syntactic trees are associated with different event structural components. A basic distinction she is arguing for is the one between inner and outer events. Outer events are associated with causation, whereas inner (or core) events are the expression of stativity and inchoativity (Tenny, 2000, 292). This distinction can be illustrated by using example (51). The outer event is the sweeping of the floor that constitutes the first subevent. It is linked via a causal relation to the inner event which is a change into a state of being clean.

(51) He sweeps the floor clean.

(He sweeps the floor) CAUSE (Become (the floor is clean))

(Dowty, 1979, 93)

Tenny associates inner/core events with the expression of changes and the achievement of a final state. Classes of verbs that contain inner events are those which also have a BECOME predicate in their event structural representation: change of state verbs, (transitive) incremental theme verbs, verbs of motion to a goal (to run) and verbs of putting (to put). The class of verbs which Tenny considers contain an inner event is not coextensive with Rappaport Hovav \& Levin's class of result/scalar change verbs but Rappaport Hovav \& Levin's result verbs form a subclass of those verbs that have a core event. 
Different test criteria for the presence of core events are mentioned by Tenny. First, only verbs that have a core event allow for the causative/ inchoative alternation (52). Incremental theme verbs, as already mentioned, do not participate in this alternation but they can be used in the middle construction (53) which is also considered to be a diagnostic of core events.

a. The workers widened the gap.

a' The gap widened.

b She darkened the photograph.

b' The photograph darkened.

(53) a. This book reads easily.

b. The soup that eats like a meal.

(Tenny, 2000, 298)

The further criterion mentioned by Tenny is telicity. If a predication is telic, then it contains a core event. The reason is that telicity always requires some change towards the telos. But, as mentioned above, not each expression of a property change results in a telic predication. This is, for example, the case with degree achievements. Verbs that contain a core event differ with regard to the criteria mentioned above and my aim is not to evaluate this part of Tenny's analysis. Rather I am focusing on her claim that verbs which have a core event in their event structure also have a measure or path as part of their lexical meaning. She writes: "If it [the verb] contains a measure or path, the final state for the core event is a gradable predicate, admitting degree modification" (Tenny, 2000, 296). A measure/path represents a gradable property with respect to which a change is expressed. Tenny assumes that change of state verbs, incremental theme verbs and verbs of motion towards a goal have a measure/path as part of their lexical meaning, whereas verbs of putting do not. The first three classes of verbs allow measuring the progression in the gradable property, which can be illustrated by combining them with measure adverbs (54). In cases such as (54a), measure adverbs "modify the endstate of the core event in the verb's lexical meaning” (Tenny, 2000, 303).
a. Jessie ran partway to the drugstore.
b. *Jessie put the book partway on the table.

(Tenny, 2000, 300) 
Tenny claims that measure adverbs only combine with verbs that contain a core event as well as a measure/path in their event structure. Hence, these verbs need to have a BECOME predicate in their event structural representation and therefore denote a change that leads to the achievement of a specific result. As verbs of putting reveal, core events alone are not sufficient for licensing measure adverbs, also a measure is required. Tenny restricts her discussion of measure adverbs to such English expressions as completely, partly and halfway. Ernst (2002) builds on Tenny's work and includes degree expressions as (very) much in the analysis. Neither Tenny nor Ernst make use of Bolinger's term 'degree verbs' but if they are right, the class of degree verbs - at least in English - should be limited to such verbs that contain a core event as well as a measure in their event structure. Hence, neither state predicates nor activities should be gradable, since they do not contain a core event. But this assumption is contrary to examples like those in (55). In (a) and (b) very much grades the stative verbs like and believe. Those verbs do not have a core event, as argued above, but they do lexicalize some scale, i.e., 'measure' in Tenny's terminology.
a. John likes Mary very much.
b. Fohn believes very much in Mary's innocence.

As shown in (56), like does not pass one of the three core event tests. First, like does not participate in the causative/inchoative alternation; second, it does not allow the middle constructions, and third, a telic reading of like (without coercion) is not possible. This shows that adverbials such as very much are not restricted to verbs containing core events.
a. ${ }^{*}$ Mary likes.
b. \#fohn likes easily.
c. \# fohn likes Mary in ten minutes.

Originally, Tenny only discussed such adverbs as completely or partially, hence her analysis could probably be rescued by restricting the discussion to these adverbs. ${ }^{22}$ But as the examples in (57) reveal completely can combine with stative predicates such as cover and consist. I take the examples in

22 Cf. Piñón (2005) for a discussion of the syntax and semantics of adverbs of completion with a short critical discussion of Tenny's account on these adverbs. 
(57) as counterevidence against Tenny's analysis, knowing that the verbs in (57) could possibly be analyzed as denoting result states which presuppose a change of state. Such a change of state could be existentially bound in the verb's event structure (cf. Koontz-Garboden 2012) and therefore the predicates could be in agreement with the requirement of a core event in their event structure.
a. In contrast, an embedded tooth is an unerupted tooth that is covered, usually completely, with bone. ${ }^{23}$
b. The album consists completely of original Dan Band songs, with no covers. $^{24}$

The examples discussed above show that Tenny's account is too restrictive and so I turn to the less restrictive account of Tsujimura (2001) in the next section.

\subsubsection{Tsujimura's (2001) analysis of Japanese degree verbs}

Tsujimura (2001) provides a discussion of Japanese degree verbs, which she considers to be verbs that license the degree expression totemo 'very, very much.' Like German sehr, totemo is a degree expression that can be used to intensify adjectives (58a) as well as verbs (58b). Like sehr, totemo is restricted to degree gradation and does not function as a device for extent gradation.

(58) Japanese (isolate; Tsujimura 2001, 32f.)
a. totemo takai
very expensibe
'very expensive'
b. Taroo-wa totemo kurusinda.
Taro-TOP very suffered
'Taro suffered very much.'

Tsujimura identifies the three conditions in (59) that have to be fulfilled by a verb to license totemo. Only the first condition is directly related to event structure and restricts the adverbial modification by totemo to such verbs

\footnotetext{
23 http://en.wikipedia.org/wiki/Tooth_impaction (30.11.2012)

24 http://en.wikipedia.org/wiki/The_Dan_Band (30.11.2012)
} 
that have a state component. The other conditions are concerned with scale structure. I discuss these conditions consecutively using Tsujimura's examples for illustration.

a. A verb must have a STATE component in its event structure.

b. The STATE component must refer to a gradable property.

c. The gradable property defined over scalar structure must be with nontrivial standard.

(Tsujimura, 2001, 47)

The first condition states that all aktionsart classes except activities potentially admit gradation by totemo. ${ }^{25}$ Tsujimura provides the examples in (60) to show that activities really reject totemo.
a. *Taroo-wa totemo hasitta.
Taro-TOp very ran
'Taro ran very much.'
b. *Taroo-wa totemo waratta.
Taro-Top very laughed
'Taro laughed very much.'
c. "Taroo-wa doa-o totemo tataita.
Taro-TOP door-ACC very hit/knocked
'Taro hit/knocked on the door very much.' ${ }^{26}$
(Tsujimura, 2001, 38)

Not all verbs that contain a state component in their event structural representation license totemo (61). The second criterion states that the state component has to be related to a gradable property. Tsujimura does not further discuss the notion of 'gradable property' and hence does not provide any test criterion to distinguish between states that are related to gradable properties and those which are not. The verbs in (61) are achievements in the sense of Vendler and express changes on a two-point scale. Tsujimura

$25 \quad$ Tsujimura (2001) builds on Rappaport Hovav \& Levin's (1998) event structure account. They follow Dowty (1979) in assuming that causativity is the relevant factor distinguishing achievements and accomplishments rather than durativity.

26 Tsujimura's data judgement is not shared by all native speakers of Japanese, as one of my informants judged at least (b) as totally acceptable. For illustrating her argumentation, I follow Tsujimura's data judgement but will show later that her analysis is not warranted. 
does not raise the question whether the rejection of totemo depends on the fact that these verbs are related to two-point but not multivalue scales.
a. *Omotya-ga totemo kowareta.
toy-NOM very broke
'The toy broke very much.'
b. ${ }^{*}$ Neko-ga totemo sinda.
cat-NOM very died
'The cat died very much.'
(Tsujimura, 2001, 39)

The third condition in (61) is a scale structural one. Tsujimura claims that for some verbs the non-acceptability of totemo cannot be explained by assuming that the state component that is part of the verb's event structure refers to a non-gradable property. Rather it seems intuitive that the respective property can be graded, which does not hold for the state of being broken or dead. With regard to the latter examples Tsujimura $(2001,39)$ writes: "the dead of a cat and the broken state of a toy do not convey gradable properties." For the verbs in (62) she assumes that the respective scales block an application of totemo because the scales are related to the wrong kind of standard.

The gradable properties of verbs as those in (62) are related to a nontrivial standard (the notion of 'non-trivial standard' is taken from Kennedy \& McNally (1999), which entails that the respective scale has to be closed. A non-trivial or absolute standard is per default one of the endpoints of the scale. That the examples in (62) are related to a non-trivial standard can be seen by the fact that they license the endpoint modifier kanzenni 'completely' (63).
a. *Harigane-ga totemo magatta. wire-NOM very bent 'The wire bent very much.'
b. *Toosuto-ga totemo kogeta. toast-NOM very burned 'The toast burned very much.' (Tsujimura, 2001, 40) 

a. Harigane-ga kanzenni magatta. wire-NOM completely bent 'The wire bent completely.'
b. Toosuto-ga kanzenni kogeta. toast-NOM very burned 'The toast burned completely.' (Tsujimura, 2001, 40)

The third condition in (59) could be paraphrased as: totemo does not combine with closed-scale predicates and does combine with those that are related to open scales. This results in a complementary distribution of totemo and kanzenni as the data in $(62) /(63)$ on the one hand and $(64) /(65)$ on the other hand show.

(64) a. Taroo-wa totemo kurusinda.

Taro-TOP very suffered

'Taro suffered very much.'

b. Hosi-ga totemo hikatta/kagayaita/kirameita.

star-NOM very shone/glittered/sparkled

'The star shone/glittered/sparkled very much.'

c. Suupu-ga totemo atatamatta.

soup-NOM very warmed

'The soup got warmed very much.'

(Tsujimura, 2001, 34)
a. *Taroo-wa kanzenni kurusinda.
Taro-TOP completely suffered
'Taro suffered completely.'
b. ${ }^{*} H o s i-g a$ kanzenni hikatta/kagayaita/kirameita. star-NOM completely shone/glittered/sparkled 'The star shone/glittered/sparkled completely.'
c. "Suupu-ga kanzenni atatamatta. soup-NOM completely warmed 'The soup got warmed completely.'
(Tsujimura, 2001, 43)

Tsujimura's class of degree verbs covers all verbs that contain a state component that is related to a gradable property. In difference to Tenny, also 
stative predicates are taken to be degree verbs, since the mere presence of a state component is less restrictive than the presence of a core event. But similarly to Tenny, Tsujimura predicts that activities do not admit degree gradation.

Contrary to Tsujimura's claim, activities can be graded by totemo; examples are totemo okotta 'bluster a lot' or totemo yorokonda 'rejoice very much. ${ }^{, 27}$ As also mentioned above, some native speakers of Japanese disagree with Tsujimura's judgement of the data and conceive examples like the one in (66) as absolutely acceptable. This furthermore shows that activities are gradable by totemo and that Tsujimura's event structural analysis of the distribution of adverbial totemo is not tenable.

$$
\begin{aligned}
& \text { Taroo-wa totemo waratta. } \\
& \text { taro-тоP very laughed } \\
& \text { 'Taro laughed very much.' }
\end{aligned}
$$

Even if Tsujimura's analysis were warranted for Japanese, it is not possible to extend Tsujimura's analysis to German, French or Russian. In those languages, degree gradation is not restricted to verbs containing a state component, as many activities admit degree gradation without undergoing some process of coercion. In (67) a German example of a graded activity predicate is shown, in this case it is the manner of motion verb rennen 'run' which is modified by sehr. Russian and French examples of graded activities are shown in (68). In the case of Russian (68a), only a degree reading arises, whereas the French example in (b) is ambiguous between an extent and a degree reading.

(67) Er musste sehr zum Bus rennen, um nicht zu spät zu kommen. he must very to.the bus run so as not to late to come 'He had to run very fast to the bus in order not to be late.'

(68) a. Segondja očen' doždil.

today very rained

'It rained a lot today.'

b. Il a plu beaucoup.

it has rained a lot

'It rained a lot.'

I owe these data to Sebastian Löbner (p.c.), who also reports that the Japanese verbs are really activities since corresponding states would be expressed by adjectival forms. 
The examples in (67) and (68) reveal that event structure does not provide a restriction on degree gradation since some activities can be graded like verbs belonging to all other aktionsart classes. Furthermore, gradable properties are not solely expressed by state components, which is evident in the case of activity predicates. I turn to a short general discussion of gradability in the conclusion of this chapter.

\subsection{Conclusion}

The aim of the current chapter was twofold: on the one hand the chapters provide relevant background for latter chapters by introducing the notions of, for example, 'aktionsart' and 'event structure.' The second aim was to present a discussion of the conditions licensing degree gradation of verbs. Two different event-structural proposals have been discussed and it has been shown, by discussing the work of Tenny and Tsujimura, that degree gradability of verbs does not depend on event structure. Degree gradation is not restricted to verbs of a certain aktionsart class; rather verbs of all aktionsart classes are gradable (69). In (a) it is shown that states can be graded, and (b) shows the same for accomplishments. The example in (c) shows degree gradation of an achievement, whereas an activity and a semelfactive are graded in (d) and (e). The presence of einmal 'once' in (e) focuses on a semelfactive reading of bellen 'bark' that otherwise also allows an iterative reading in which it is used as activity verb.
a. Maria liebt Peter sehr.
Maria loves Peter very
'Maria loves Peter very much.'
b. Der Zustand hat sich sehr stabilisiert.
the condition has REFL very stabilized
'The condition stabilized a lot.'
c. Maria hat Peter sehr erschreckt.
Maria has Peter very scared
'Maria scared Peter very much.'
d. Maria ist sehr gerannt.
Maria is very ran
'Maria ran very fast.' 


\section{e. Der Hund hat (einmal) sehr gebellt. the dog has once very barked 'The dog once barked very much.'}

It is not only the case that aktionsart classes do not constrain degree gradability of verbs but also Rappaport Hovav \& Levin's disctinction between scalar and non-scalar verbs is also independent from degree gradability. In (69) examples of gradable scalar and non-scalar change verbs are shown. Stabilisieren 'stabilize' in (69b) is a result verb, i.e., scalar change verb, and admits degree gradation. The verbs rennen 'run' in (d) and bellen 'bark' in (e) are manner verbs, i.e., non-scalar verbs, and also admit degree gradation. In Rappaport Hovav \& Levin's work, the notion of 'scalarity' is restricted to directed changes in a single dimension. They do not claim any relationship between scalarity and gradation and in fact the discussion in this chapter reveals that degree gradation is not restricted to scalar changes. This demonstrates that, for verbs, access to a scale is not dependent on the expression of directed changes in a single dimension. Instead scales are lexical componnets of a much broader set of verbs which cannot be covered by Rappaport Hovav \& Levin's class of 'scalar change verbs.' Nevertheless, Rappaport Hovav \& Levin's class of scalar (change) verbs is relevant for the latter discussion, as these verbs form a special subtype of verbal degree gradation that interacts with grammatical aspect as well as with telicity. This will be discussed in more details in chapters 6 and 9 .

The discussion in this chapter revealed that the only relevant factor for licensing degree gradation is the presence of a suitable gradation scale. Whether a verb is related to a scale that is admissible for gradation or not does not depend on such factors as telicity, durativity, dynamicity or whether the verb encodes 'manner' or 'result.' Even if the presence of a scale is not predictable, as it is not dependent on some other semantic property, verbs belonging to the same semantic class show remarkable uniformity regarding degree gradation (as indicated in 3.1). Hence, the notion of 'semantic verb classes,' in the sense of Levin (1993), plays an essential role in the analysis of verbal degree gradation and the case studies presented in chapter 6 to 8 are organized around such a semantic classification of verbs. 